\title{
Flight veteran embraces NASA's science wing
}

Tony Reichhardt, Washington

John Grunsfeld, NASA's new chief scientist, isn't merely passionate about space science: "I've been willing to risk my life to do science," he says. From others, that statement might sound boastful or delusional. But it is true enough in Grunsfeld's case - he has travelled on the space shuttle four times, including a 16-day research flight in 1995 and two trips to upgrade the Hubble Space Telescope.

Grunsfeld took over this month as NASA's fourth chief scientist since former administrator Dan Goldin created the position ten years ago. Since then the job has carried little political clout and no budgetary authority. But these are turbulent times at the space agency, with major decisions about its future goals looming large on the horizon. Grunsfeld - an astronomer who succeeds two biologists in the position - might just be the man of the moment, observers of the space agency say.

He brings to the job a solid research background. A 44-year-old native of Chicago, he obtained a doctorate in physics from the University of Chicago and did postdoctorate work there and at the California Institute of Technology (Caltech) in Pasadena, before beginning his astronaut training in 1992.

A specialist in $\gamma$-ray and X-ray astronomy, he has worked at the Very Large Array in Socorro, New Mexico, as well as on spaceborne instruments such as the Hubble and the Compton Gamma Ray Observatory. He has published his work in places such as the Astrophysical Journal — no mean feat considering the time demands of shuttle training.

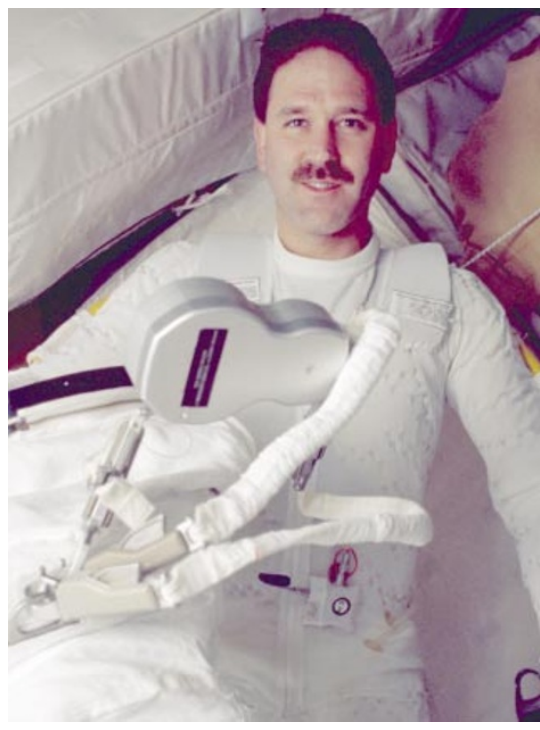

Space man: John Grunsfeld's own missions have convinced him that human spaceflight is vital.

Anneila Sargent, an astronomer at Caltech, says that researchers should find Grunsfeld easy to talk to. "I see John as approachable," she says, adding that he talks scientists' language. As chief scientist, he will be responsible for advising NASA administrator Sean O'Keefe on the agency's entire research portfolio - not just astronomy but also Earth science, as well as the biological and materials-science experiments planned for the International Space Station.

Grunsfeld says that he is well aware of scientists' scepticism about the space station (see Nature 418, 263; 2002), but thinks that it is unfair to judge its usefulness while it is still under construction. He says that critics of the station may have the wrong idea about it because of their own backgrounds: laboratory scientists, he points out, are used to working in fully controlled environments. "Field scientists have a more accurate idea of how much scientific return we can get," he says, as they are used to unpredictability and to handling logistical challenges. Doing science in space, he contends, is more akin to "an athletic event".

His two successful Hubble missions are his proudest achievements as an astronaut, Grunsfield says, adding that the telescopeservicing operations were a 'poster child' for cooperation between NASA's astronaut programme and its scientific projects. Furthering such endeavours, he says, will be "absolutely top of my list" of priorities as chief scientist. In the past year he has been involved in planning for future space telescopes that could be serviced by a combination of humans and robots - just the sort of human-spaceflight objective that NASA badly needs in the wake of the Columbia accident.

Such projects will need large infusions of money, as well as advocates like Grunsfeld, if they are to come to fruition. If NASA pursues an ambitious programme of human exploration, says Joe Alexander, director of the National Academy of Sciences' Space Studies Board, Grunsfeld's talents as an astronaut and astronomer could prove to be a useful combination. \section{Galileo gears up for swansong as crash-landing looms}

\section{John Moore}

NASA's most successful planetary probe, Galileo, is due to end its mission on 21 September by crash-landing into Jupiter. There is just enough propellant on board to point its antenna towards Earth, so NASA scientists hope to retrieve more data in the craft's final days.

Galileo's lifetime has been extended three times by NASA since it arrived at Jupiter in December 1995, helping it to collect more information than any other planetary mission to date. Its observations led to the discovery that Jupiter's moon Europa probably has an ocean beneath its icy surface, and that Io harbours a giant volcano. In 1994, Galileo was close enough to the planet to see comet Shoemaker-Levy 9 break up and pummel the surface, giving scientists a better idea of what might happen in a similar collision with Earth.

If left alone, Galileo could have stayed in

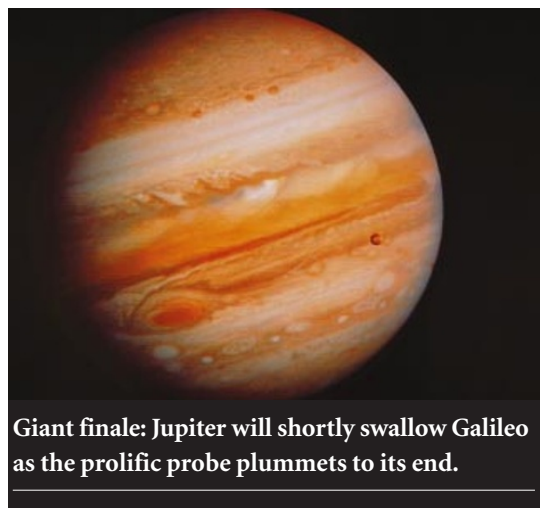

orbit around Jupiter for the next 60 years. But there was a risk that the craft would accidentally crash into and contaminate Europa, which planetary scientists think might harbour life. Intentionally crashing a spacecraft and getting data along the way isn't unprecedented — Magellan was smashed into Venus in 1994, for example.

In Galileo's final 24 hours, it will be trained on Amalthea, one of Jupiter's inner satellites. Researchers think that it may have a comet-like structure, shedding pieces that could make up one of Jupiter's faint rings.

If Galileo is still transmitting data in its final hour, scientists hope to determine where the outer edge of Jupiter's atmosphere begins. At present, no one knows how far the planet's gases extend beyond its surface, says Galileo's project manager, Claudia Alexander.

But it is not clear whether Galileo's instruments will still be functioning by then. Researchers expect the craft to be torn apart in the atmosphere on its speedy descent at 50 kilometres per second. Details of Galileo's fate will never be known, as its final few minutes will be spent on the far side of the planet, out of sight from Earth. 